\title{
Under nutrition In Obese Elderly Diabetic Patient
}

\author{
FZ Kaidi ${ }^{{ }^{*}}$, NE. Haraj ${ }^{2}$, S. El Aziz ${ }^{1}$, A. Chadli ${ }^{1}$ \\ ${ }^{1}$ Endocrinology, Diabetology and Metabolic Diseases department.UHC Ibn Rochd, Casablanca, Morocco \\ ${ }^{2}$ Neuroscience and Mental Health laboratory, Faculty of Medicine and Pharmacy, University Hassan II Casablanca, Morocco
}

Received: October 26,2019; Accepted:November 9,2019; Published: November 25,2019

*Corresponding author : Dr Fatima Zahra kaidi, Endocrinology, Diabetology and Metabolic Diseases department.UHC Ibn Rochd, Casablanca, Morocco;Tel : 0679545315; Fax : 0522222021; E-mail: kaidizohra6@gmail.com

\section{Summary}

\section{Introduction}

After the age of 65 years, $17 \%$ of patients are obese and 4 to $10 \%$ are undernourished. The number of elderly patients in both obese and undernourished is little known in the general population but also in diabetic patients.

\section{Objective}

This study was to assess the prevalence of under nutrition and describe the factors that influence nutritional status in obese elderly diabetic patients.

\section{Patients and methods}

We conducted a cross-sectional study between September 2016 and February 2018, including 120 type 2 diabetic obese, aged 65 and over, collected in our unit. Nutritional status was assessed by the Mini Nutritional Assessment and by serum albumin assay. Statistical analysis was performed by epi Info 0.6 . Software.

\section{Results}

The average age of patients was 71 years, $66 \%$ were female. The mean BMI was $33.4 \mathrm{~kg} / \mathrm{m} 2,61 \%$ had at least a degenerative complications. Dyslipidemia was present in $51.6 \%$ of patients and hypertension in $58.3 \%$. Malnutrition was found in $10.8 \%$ of patients and $28.3 \%$ were at risk of malnutrition. We found a significant correlation $(\mathrm{p}<0.05)$ between undernutrition and poly medication, the cholesterol-lowering and diabetic diet, dyslipidemia, nephropathy and the presence of chewing or swallowing disorders.

\section{Conclusion}

Under nutrition of the obese subject is an unknown clinical entity whose prevalence will increase significantly, specific studies about undernutrition among obese elderly patients become necessary especially diabetics.

Keywords: Under nutrition; Sarcopenic obesity; Elderly; Diabetic; Risk factor; Consequence.

\section{Introduction}

After the age of 65 years, $17 \%$ of patients are obese and 4 to10\%are undernourished. The number of elderly patients in both obese and undernourished is little known in the general population but also in diabetic patients.

The diagnosis of malnutrition in older obese subjects is problematic, the definition and diagnostic criteria of undernutrition for non-obese subjects are at fault because of clinical, morphological and biological excessive adiposity $[1,2]$. However, risk factors exposing to malnutrition in elderly obese diabetics are the same as the normal weight for age, however, some clinical situations are more frequent in the studied population $[3,4]$.

\section{Patients and methods}

We conducted a prospective observational and analytic study at the Department of Endocrinology and Metabolic Diseases, UHC Ibn Rochd Casablanca, extended over 18 months between September 2016 and February 2018.

\section{Inclusion criteria}

Any type 2 diabetic hospitalized at the service for chronic glycemic imbalance or for acute decompensation of diabetes after stabilization and any diabetic type 2 followed at the consultation, aged 65 years old and over (age of retirement in Morocco), whose BMI $\geq 30 \mathrm{~kg} / \mathrm{m}^{2}$, independent, without mental or memory 
disorders. 120 diabetic patients were included.

\section{Exclusion criteria}

Type 1 diabetic patients, patients with age $<65$ years old, with BMI $<30 \mathrm{Kg} / \mathrm{m}^{2}$, patients who refuse to be interviewed, nonautonomous patients and patients with psychic and / or memory disorders were excluded from the study.

\section{Variables studied}

- Sociodemographic features were studied such as age, sex and BMI. The socio-economic level was also identified.

- Regarding diabetes, the parameters assessed were the age of diabetes, the treatment used, the level of glycemic control (by the dosage of glycosylated hemoglobin (HbA1c) by standardized HPLC method) and degenerative complications.

- Nutritional status of patients was evaluated by serum albumin assay and by the validated Arabic version of the Mini Nutritional Assessment (MNA).

An albumin of $<35 \mathrm{~g} / \mathrm{l}$ leads to protein-energy malnutrition, an albumin of $<30 \mathrm{~g} / \mathrm{l}$ leads to severe undernutrition.

The MNA score is frequently used tests for assessing nutritional status and identifying undernutrition in an elderly person. According to this test, anthropometric data (especially BMI) are one criterion among others. The evaluation takes place in two stages:

1. Screening based on 6 questions (A to F), graded from 0 to 2 or 0 to 3 and corresponding to a maximum

a. If the score is greater than or equal to 12 , there is no problem of malnutrition and it is useless to continue the test.

b. If it is less than 12 , there is a possibility of malnutrition and whether to continue the test

2. The overall assessment: Relies on 12 additional issues (L to R) scored 16 points in total. In the end, when a global assessment is made with the NAM, it is noted on 30 points:

- A MNA score less than 17 points corresponds to poor nutritional status

- MNA score between 17 and 23.5 at risk of malnutrition

- MNA score greater than or equal to 24 indicates a satisfactory nutritional status

\section{collection and data analysis}

Data were collected by detailed operating form completed by the same doctor and were collected into an Excel spreadsheet (Microsoft).

Informed consent was signed by the participating patients.

The anonymity of the subjects was totally preserved for the duration of the study.
Statistical analysis was assured by epi.Info6.0. software.

For the descriptive part, the means, standard deviations and percentages were calculated to summarize the distributions of the qualitative variables. The analytical study was based on the Pearson Chi 2 test with a significant $\mathrm{p}<0.05$.

\section{Results}

120 patients were included in the study, whose average age was 71 years (65-82), 66\% were female. Mean BMI was $33.4 \mathrm{~kg} /$ $\mathrm{m} 2$ (30-42), $22.5 \%$ of patients had a BMI greater than $35 \%$. The mean duration of progression of diabetes was 9 years (1-14), HbA1c $\leq 8 \%$ was present in $36.6 \%$ of our patients.

Tables I and II illustrate the demographics of our patients and the characteristics of diabetes

Dyslipidemia was observed in $51.6 \%$ (62) of patients and hypertension in 58.3\%; $61 \%$ of patients had at least one degenerative complication.

Table III illustrates cardiovascular risk factors and microangiopathic complications in the study population.

Under nutrition was found in $10.8 \%$ (13) of patients and $28.3 \%$ (36) presented a risk of malnutrition. Figure 1 presented the distribution of patients according to the nutritional status assessed by the MNA score.

According to albuminemia, $32 \%$ of patients had proteinenergy malnutrition, among them $8 \%$ were severely undernourished Figure 2

We found a significant correlation $(p<0.05)$ between undernutrition and low socio-economic status, polypharmacy, cholesterol-lowering and diabetic diet, the presence of nephropathy, and mastication or swallowing disorders.

Polypharmacy was present in $75.5 \%$ of malnourished patients versus $66 \%$ of patients with normal nutritional status.

With a significant difference $(\mathrm{p}=0.01)$.

Nephropathy was present in $77.5 \%$ of malnourished patients versus $49.3 \%$ of patients with normal nutritional status

With a significant difference $(\mathrm{p}=0.001)$.

Table IV represents the risk factors associated with undernutrition in obese elderly diabetic patients. 


\section{Table I: Clinico-demographic characteristics of patients}

\begin{tabular}{|c|c|c|c|}
\hline $\begin{array}{l}\text { Clinico-demographic } \\
\text { Characteristis }\end{array}$ & Number & Average & $\%$ \\
\hline Number & 120 & & \\
\hline Middle age & & 71 ans (65-82) & \\
\hline $65-70$ years & 56 & & $46,6 \%$ \\
\hline 71-75 years & 44 & & $36,7 \%$ \\
\hline 76-80 years & 18 & & $15 \%$ \\
\hline Beyond 80 years & 2 & & $1,7 \%$ \\
\hline Women & 79 & & $66 \%$ \\
\hline Average BMI & & $33,4 \mathrm{Kg} / \mathrm{m} 2$ & \\
\hline $30-34 \mathrm{~kg} / \mathrm{m} 2$ & 85 & & $70,8 \%$ \\
\hline $35-40 \mathrm{~kg} / \mathrm{m} 2$ & 27 & & $22,5 \%$ \\
\hline Beyond 40 kg / m2 & 8 & & $6,7 \%$ \\
\hline \multicolumn{4}{|l|}{ Mid-province } \\
\hline Rural & 33 & & $27,5 \%$ \\
\hline Urban & 87 & & $72,5 \%$ \\
\hline \multicolumn{4}{|l|}{ Socio-economic level } \\
\hline Low & 90 & & $75 \%$ \\
\hline Medium & 25 & & $21 \%$ \\
\hline High & 5 & & $4 \%$ \\
\hline
\end{tabular}

\begin{tabular}{|c|c|c|c|}
\hline \multicolumn{4}{|c|}{ Table II: Diabetes characteristics } \\
\hline Diabetes characteristis: & Number & Average & $\%$ \\
\hline \multicolumn{2}{|c|}{ The average duration of evolution } & \multicolumn{2}{|c|}{9 years $(1-21$} \\
\hline$<5$ years & 41 & & $34 \%$ \\
\hline $5-10$ years & 44 & & $36,6 \%$ \\
\hline Beyond 10 years & 35 & & $29,4 \%$ \\
\hline \multicolumn{4}{|l|}{$\mathrm{HbA1c}$} \\
\hline$\leq 8 \%$ & 44 & & $36,7 \%$ \\
\hline $8<\mathrm{HbA} 1 \mathrm{c} \leq 10 \%$ & 40 & & $33,3 \%$ \\
\hline $\mathrm{HbA} 1 \mathrm{c}>10 \%$ & 36 & & $30 \%$ \\
\hline \multicolumn{4}{|l|}{ Treatment: } \\
\hline oral antidiabetic drugs & 34 & & $28,3 \%$ \\
\hline Insulin & 63 & & $52,5 \%$ \\
\hline mixed treatment & 14 & & $11,6 \%$ \\
\hline diet & 9 & & $7,6 \%$ \\
\hline
\end{tabular}

Table III: Cardiovascular Risk Factors and Microangiopathic Complications in the Study Population

\begin{tabular}{|l|l|l|}
\hline $\begin{array}{l}\text { Cardiovascular Risk Factors and } \\
\text { Microangiopathic Complications }\end{array}$ & Number & $\%$ \\
\hline Cardiovascular risk factors: & 120 & $100 \%$ \\
\hline Obesity & 70 & $58,3 \%$ \\
\hline HTA & 62 & $51,6 \%$ \\
\hline dyslipidemia & 79 & $66 \%$ \\
\hline Menopause & 18 & $15 \%$ \\
\hline Tobacco & 35 & $29 \%$ \\
\hline Ischemic cardiomyopathy & 73 & $61 \%$ \\
\hline Diabetic nephropathy: & 45 & $37,5 \%$ \\
\hline DiabeticRetinopahty: & 43 & $36 \%$ \\
\hline Autonomicneuropathy: & 57 & $47,5 \%$ \\
\hline Peripheralneuropathy: & &
\end{tabular}

Table IV: Risk Factors Associated with Under nutrition (according to the MNA score)

\begin{tabular}{|c|c|c|c|}
\hline Risk factor & $\begin{array}{l}\text { Number of } \\
\text { undernourished }\end{array}$ & $\begin{array}{l}\text { Number } \\
\text { of patients } \\
\text { normonutris }\end{array}$ & $\mathrm{P}$ \\
\hline $\begin{array}{l}\text { Duration of } \\
\text { evolution of DT } \\
\text { beyond } 5 \text { years }\end{array}$ & 28 & 51 & 0,9 \\
\hline Female sex & 36 & 43 & 0,1 \\
\hline Age $>70$ years & 26 & 38 & 0,5 \\
\hline Nephropathy & 38 & 35 & 0,001 \\
\hline $\begin{array}{l}\text { Autonomic } \\
\text { neuropathy }\end{array}$ & 15 & 28 & 0,5 \\
\hline $\begin{array}{l}\text { Peripheral } \\
\text { neuropathy }\end{array}$ & 18 & 39 & 0,05 \\
\hline The low level SE & 42 & 48 & 0,01 \\
\hline $\begin{array}{l}\text { Poly medication } \\
\text { ( } \geq 3 \text { drugs) }\end{array}$ & 37 & 47 & 0,01 \\
\hline $\begin{array}{l}\text { Poor oral } \\
\text { condition }\end{array}$ & 39 & 54 & 0,001 \\
\hline Hypo lipidic diet & 39 & 34 & 0,001 \\
\hline Strict diabetic diet & 37 & 8 & 0,01 \\
\hline
\end{tabular}




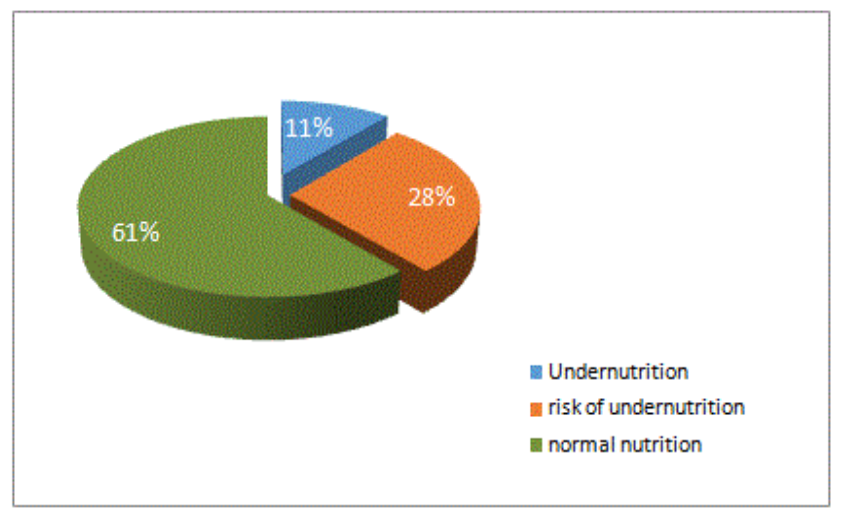

Figure 1: Valuation of nutritional status according to the MNA score

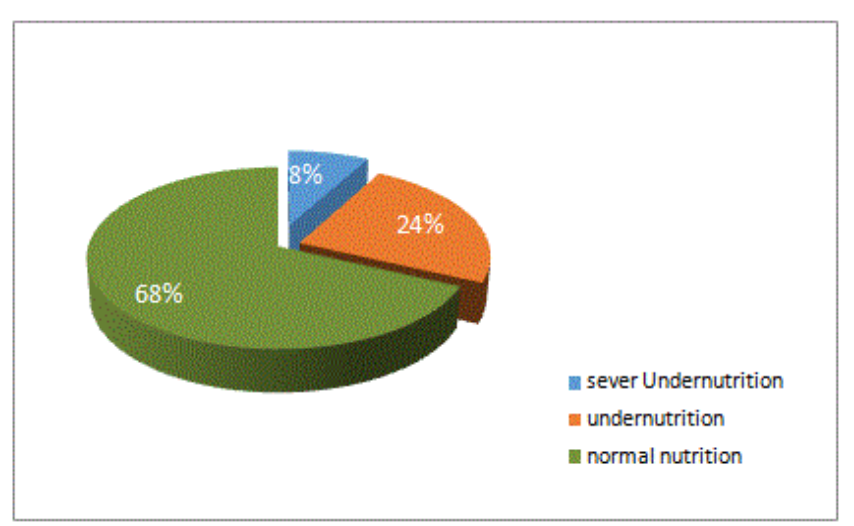

Figure 2: Valuation of nutritional status according to the albuminemia

\section{Discussion}

In the absence of a consensus definition of undernutrition in the obese elderly, the prevalence of this association is difficult to asses, yet it increases clearly due to the increase in the prevalence of obesity, aging and chronic pathologies [5-7].

\section{Positive diagnosis}

The assessment of nutritional status is based primarily on clinical criteria such as weight measurement, body mass index, weight loss, anthropometric measurement, and dietary history items possibly combined in one score as the mininutritional assessment (MNA). Lean mass assessed by impedance measurement has a prognostic value. Hypoalbuminemia is a marker of poor prognosis [8,9]

The clinical and biological diagnostic tools used to define undernutrition in the general population are at fault in obesity [10] for several reasons:

1. First, BMI may be considered as normal, even after significant weight loss in a previously obese subject. The rapid weight loss (even involuntarily) in chronic diseases be perceived relatively favorable, but it is a pejorative factor in malnutrition $[11,12]$. Excessive fat mass may mask a significant loss of lean body mass in the older subject [13-14].

2. The albuminemia is the most appropriate parameter among the "classic" biological criteria for undernutrition. In the obese patient, many events, such as inflammation, hemodilution, liver failure, or urinary losses observed in complicated obesity, may also result in decreased albumin levels [15-17] more over, in patients with obesity without any obvious comorbidity, we find 20 to $25 \%$ hypo albuminemia ( $<35 \mathrm{~g} / \mathrm{L}$ ) without recognized etiologies $[18,19]$.

3. Therefore, in order to stop malnutrition in the obese person in current clinical practice, it is important to take into account different clinical arguments:

- The fast and significant weight loss ( $\geq 10 \%$ in 6 months or $\geq 5 \%$ in 1 month)

- The clinical context: physical aggression (infection for example), immobilization

- The evaluation of the ingests to be compared with the energy expenditure of rest

- The decrease of physical capacities

- The extension of the nutritional equilibrium: Vitamins $\mathrm{B}$, vitamins $\mathrm{C}$, martial assessment, vitamino-calcium balance in addition to the usual biological factors such as albuminemia, prealbuminemia and the CRP assay

- The global MNA.

In our study, the MNA score and plasma albumin dosage were used to assess nutritional status in the obese elderly diabetic patients.

\section{Risk factors}

chez le sujet âgé la dénutrition est d'origine plurifactorielle, impliquant les modifications métaboliques liées au vieillissement, la diminution de la prise alimentaire et les pathologies intercurrentes, en particulier inflammatoires. The origins and clinical situations leading to undernutrition and / or sarcopenia in obese subjects are the same as those of normal body size. Nevertheless, some clinical situations are more common in obese elderly [20] such as precariousness, depressive syndrome, dependency [21], chronic organ diseases, including cardiovascular diseases [22, 23], polymedication, some drug treatments such as corticosteroids or cancer chemotherapy [24, 25], restrictive diets, oral disorders [26] and a history of heavy digestive surgery or bariatric surgery $[27,28]$.

The degenerative complications of diabetes such as diabetic retinopathy by decreased autonomy, the anorexic pain of hyperalgic peripheral neuropathy and diabetic nephropathy can all worsen the situation. The origin of malnutrition in 
nephropathic patients is multifactorial and complex, some factors are related to nephropathy itself (abnormalities of protein-energy metabolism, anorexia, dietary restriction, endocrine disorders) and others to hemo dialysis $[29,30]$.

Oral disorders favored by age, but also but diabetes too (three times more common among diabetics), low socioeconomic level and low educational level are known as risk factors favoring under nutrition for several years.

Finally, sedentary linked to weight gain and therefore particularly prevalent in obesity is also a risk factor for undernutrition, it is the cause of muscle weakness which in turn will cause a reduction in physical activity and a loss of strength and mass muscle and therefore.

\section{Consequences}

One of the major complications of undernutrition in the obese elderly is the decrease in muscle mass, which will be particularly hidden by the fat mass in this population and aggravated by the sedentary lifestyle. This sarcopenic obesity represents a negative prognostic factor in terms of morbi-mortality [31-32] and motor functional abilities, it participates in the alteration of immune defenses by decreasing reserves of amino acids, it promotes osteoporosis, motor disorders and of balance inducing falls with risk of fracture, it causes a decrease of the autonomy and an alteration of the quality of life [33].

This undernutrition also increases the risk of infection and the risk of dehydration, it prolongs the duration of hospitalization and delays healing. Finally, it participates in the degradation of cognitive abilities and psychological state.

\section{Conclusion}

Undernutrition in elderly and obese diabetic patients is a new clinical entity that remains unknown despite its significant prevalence.

The clinical and biological diagnostic tools used to define undernutrition in the general population are faulty in the case of obesity, which makes it difficult to take different clinical and biological arguments to evaluate the nutritional status of the study population.

specifically the psychosocial context (precariousness, depressive syndrome, addiction), chronic organ diseases favored by obesity and diabetes, certain drug treatments such as corticosteroids or anticancer chemotherapy, repeated restrictive diets and sedentary lifestyle increase the risk of undernutrition in the population studied.

The prevalence of undernutrition of the obese will increase in the following years given the aging of the population in parallel with the increase in the prevalence of obesity, it is therefore important to know how to diagnose and manage this undernutrition.

\section{References}

1. National Epidemiological Survey on overweight and obesity. A survey INSERM / Kantar HEALTH / ROCK. ObEpi.2012;

2. Lahaye $\mathrm{C}$, et al. How to define and diagnose malnutrition in obese? Nutr blink metabolism.2017;

3. AC Milne, Potter J, Vivanti A, Avenell A. Protein and energy supplementation in elderly people at risk from malnutrition. Cochrane Database Syst Rev 2009; (2): CD003288. doi: 10.1002/14651858. CD003288.pub3.

4. G Cawood, Elia M, RJ Stratton. Systematic review and meta-analysis of the effects of high protein oral nutritional supplements. Ageing Res Rev. 2012; 11(2): 278-296. doi: 10.1016/j.arr.2011.12.008.

5. INSEE. 2015

6. Aging. World Health Organization.

7. Kyle UG, Pirlich M, Lochs H, Schuetz T, Pichard C. Increased length of hospital stay in underweight and overweight patients at hospital admission: a controlled study population. Clin Nutr. 2005;24(1):133142.

8. ANAES/Department of professional recommendations / September 2003 revised in 2012 .

9. HAS. 2007;

10. Pichard C, Kyle UG, Morabia A, Perrier A, Vermeulen B, Unger P. Nutritional assessment: lean body mass depletion at hospital admission is associated with an Increased length of stay. Am J Clin Nutr. 2004;79(4):613-618.

11. Gallagher D, Ruts E, Visser H, Heshka S, Baumgartner RN, Wang J, et al. Weight stability masks sarcopenia in elderly men and women. Am J PhysiolEndocrinolMetab. 2000;279(2):E366-E375.

12. Newman AB, Kupelian V, Visser M, Simonsick E, Goodpaster B, Nevitt $M$, et al. Sarcopenia: Alternative definitions and associations with lower extremity function. J Am Geriatr Soc. 2003; 51(11): 1602-1609.

13. Cruz-Jentoft AJ, Baeyens JP, Bauer JM, Boirie Y, Cederholm T, Landi F, et al. Sarcopenia: European consensus definition and diagnosis were: Report of the European Working Group on Older People in sarcopenia. Age Ageing. 2010;39(4):412-423. doi: 10.1093/ageing/ afq034.

14. Baumgartner RN. Body composition in healthy aging. Ann NY AcadSci.2000;904:437-448.

15. Rolland Y, Lauwers-Cances V, Cristini C, Abellan van Kan G, Janssen I, Morley JE, et al. Difficulties with physical function associated with obesity, sarcopenia, obesity and sarcopenic-in community-dwelling elderly women: the EPIDOS (epidemiology of osteoporosis) Study. Am J Clin Nutr. 2009;89(6):1895-1900. doi: 10.3945/ajcn.2008.26950.

16. Rantanen T, Guralnik JM, Ferrucci L, Penninx BW, Leveille S, Sipilä S, et al. Coimpairments as predictors of severe walking disability in older women. J Am Geriatr Soc. 2001;49(1):21-27.

17. Farigon N, Montel F, Miolanne M, Y. Boirie hypoalbuminemianon assaulted obese subject: undernutrition marker or overnutrition? ClinNutr. 2014;

18. Aussel C Cynober L. Is the albumin a marker of nutritional status? Clin Nutr. 2013;

19. Cederholm T, Barazzoni R, Austin P, Ballmer P, Biolo G, Bischoff SC, et al. ESPEN guidelines are definitions and terminology of Clinical Nutrition. Clin Nutr. 2017;36(1):49-64. doi: 10.1016/j.clnu.2016.09.004. 
20.Zeanandin G, Molato O, Le Duff F, Guérin O, Hébuterne X, Schneider SM. Impact of restrictive diets on the risk of undernutrition in a freeliving elderly population. Clin Nutr. 2012;31(1):69-73. doi: 10.1016/j. clnu.2011.08.007.

21. Franz MJ, Bantle JP, Beebe CA, Brunzell JD, Chiasson JL, Garg A, et al. Nutrition principles and recommendations in diabetes. Diabetes Care. 2004; 27 Suppl 1:S36-S46.

22. Short KR, Vittone JL, Bigelow ML, Proctor DN, Nair KS. Age and aerobic exercise training effects are muscle and whole body protein metabolism. Am J Physiol Endocrinol Metab. 2004;286(1):E92-E101.

23. HA Bischoff-Ferrari, B Dawson-Hughes, HB Staehelin, JE Orav, AE Stuck, R Theiler, et al. Fall prevention with supplemental and active forms of vitamin D: a meta-analysis of randomized controlled trials. BMJ. 2009; 339.doi: 10.1136/bmj.b3692

24. Vaduva P, Tamion F, Thibault R. Nutrition of obese assaulted. Clin Nutr Metabol. 2017; 31 (4): 294-302.

25. SFNEP. clinical nutrition issues in adults. Knoe Editions; 2013.

26. Oral Prevention in the elderly, the Health Branch SD2B, MarysetteFolliguet- May 2006

27. Jésus $P$ and Coëffier M. Comment évaluer les besoins énergétiques et protéiques du sujet obèse ? Nutr Clin Metabol. 2017;
28. Benhamou CL, Souberbielle JC, Cortet B, Fardellone P, Gauvain JB, Thomas $\mathrm{T}$, et al. La vitamine $\mathrm{D}$ chez l'adulte : recommandations du GRIO. Presse Med 2011

29. Lamb EJ, Webb MC, Simpson DE, Coakley AJ, Newman DJ, O’Riordan SE. Estimation of glomerular filtration rate in older patients with chronic renal insufficiency: is the modification of diet in renal disease formula an improvement? J Am Geriatr Soc. 2003;51(7): 1012-1017.

30. Fehrman-Ekholm I and Skeppholm L. Renal function in the elderly ( $>70$ years old) measured by means of iohexol clearance, serum creatinine, serum urea and estimated clearance. Scand J Urol Nephrol. 2004;38(1):73-77.

31. Rolland Y, Lauwers-Cances V, Cristini C, Abellan van Kan G, Janssen I, Morley JE, et al. Difficulties with physical function associated with obesity, sarcopenia, and sarcopenic-obesity in community-dwelling elderly women: the EPIDOS (EPIDemiologie de l'OSteoporose) Study. Am J Clin Nutr. 2009; 89(6):1895-1900. doi: 10.3945/ajcn.2008.26950.

32. Rantanen T, Guralnik JM, Ferrucci L, Penninx BW, Leveille S, Sipilä S, et al. Coimpairments as predictors of severe walking disability in older women. J Am Geriatr Soc. 2001;49(1):21-27.

33. N. Farigon et al. Undernutrition in obese patient, Nutrition clinique et métabolisme. 29 (2015):50-53 